\title{
NO TRAJETO DA MEMÓRIA
}

\section{Vadivaldo Gonçalves Pereira ${ }^{1}$}

Resumo: O presente texto trata do memorial sobre a trajetória escolar de Vadivaldo Gonçalves Pereira, ex-integrante do Programa Conexões de Saberes. Tem como objetivo apresentar os passos percorridos desde o início da educação básica até a entrada à UFPA e quais os principais entraves de estudantes das comunidades populares adentrarem o ensino superior público. A memória foi usada como principal referência para construção do material. Em seus resultados, apresenta os esforços individual e coletivo para que de fato a educação seja uma questão de direito e não de privilégio de poucos.

"Dizer as coisas como são". (Platão, apud Rocha \& Naumari, 2006, p.13).

Relatar uma trajetória de estudante não é fácil, mesmo sabendo que esse estudante é você. Para ser sincero, esperei muito por esse momento. Desde o instante que ingressei neste programa a ansiedade não me dá sossego, a oportunidade é esta; é preciso transmitir todas as dificuldades pelas quais um estudante de origem popular passa.

Neste memorial registro as experiências vividas por um batalhador oriundo de escolas públicas, tais experiências são riquíssimas, visto que são poucos que chegam ao topo da pirâmide, sendo chamados mais que vencedores, porque foram persistentes e não foram vencidos por suas angústias e aflições. Como diz Tiago de Melo (2007):

O que passou não conta? indagarão as bocas desprovidas. Não deixa de valer nunca. O que passou ensina com sua garra e seu mel. Por isso é que agora vou assim no meu caminho. Publicamente andando.

\section{O PASSADO PRESENTE NA LEMBRANÇA}

É satisfatório lembrar o ano de 1981 ano que vim do interior para morar na cidade, era a época da tabuada, da palmatória, dos primeiros passos para a escola. Que felicidade! Toda aquela euforia me envolvia, pois meu maior sonho naquele momento era morar e estudar em

\footnotetext{
1 Especialização em Literatura e Leitura pela Universidade Federal do Pará, e-mail: conexoesmulticampi@yahoogrupos.com.br
}

Revista PET Interdisciplinar e Programa Conexões /UFPA On-line. Ed. Especial - 2017, BELÉM/ PA - ISSN 2447-097X 
Cametá. É evidente que esses pensamentos eram de um garotinho de apenas oito anos de idade que queria estar perto das novidades eletrônicas criadas durante e depois da revolução industrial. Com a globalização, os produtos da revolução industrial estão presentes até mesmo no interior das cidades. Para lembrar Ricardo Reis ${ }^{2}$ Se recordo quem fui outrem me vejo. E o passado é o presente na lembrança.

\section{OPORTUNIDADES}

O programa Conexões de Saberes é um projeto da Pró-Reitoria de Extensão que articula e propõe a troca de experiências vividas por estudantes de hoje a de futuras gerações no intuito de cada vez mais motivá-los a construir a sua própria história. Conforme o livro de eclesiastes ${ }^{3}$ quando diz Há tempo de plantar e tempo de arrancar o que se plantou.

\section{O OBJETO}

Todo pesquisador quando vai fazer um estudo, focaliza um ponto " $\mathrm{x}$ " como seu objeto de estudo. Nesse memorial eu sou o objeto, sou a fonte de minha própria pesquisa, como também o pesquisador. Como já havia mencionado, viemos para a cidade em 1981, mas somente no ano de 1984 comecei a dar os meus primeiros passos para a escola. A situação financeira foi pior do que quando morávamos no interior, felizmente o convívio familiar manteve-se bem.

\section{EDUCAÇÃO, FUGA DAS DIFICULDADES E MARGINALIDADE}

Quando chegamos a Cametá, éramos sete filhos mais nossa mãe. Era muito difícil para ela manter sete filhos ganhando uma pensão do governo de um salário mínimo, sabendo que desses sete filhos cinco precisavam estudar. Minha mãe teve de dar dois irmãos meus para morar com outra família, pois assim poderiam ter a chance de estudar. As crianças mais novas, entre elas eu, permaneceram sob os cuidados de minha mãe e tivemos que batalhar 
juntos no dia-dia. Por esse motivo só comecei estudar três anos depois. Para Pierre Furter (1966) [...] a educação terá como função principal / o permitir ao homem o fazer-se a partir da situação concreta e global na qual está colocado.

Minha vida foi construída por diferentes experiências. Graças à minha mãe tive sede de construir um futuro melhor ela costumava: estuda meu filho, para que você não seja analfabeto como eu e saiba escrever pelo menos o seu nome. Aquelas palavras me incentivavam a lutar pela minha formação e poderia mudar a imagem do passado. A educação é uma das formas que o individuo usa para se auto-educar e sair da marginalização. Dessa forma afirma Chauí (1980):

Assim, a regra da competência, somada ao mito da racionalidade encarnada no 'taylorismo' e na burocracia (...), e acrescida dos padrões de organização da administração, silencia o discurso da educação, para que o poder fale sobre ela.

\section{IMAGEM E PRECARIEDADE DE UMA ESCOLA}

A partir do momento que entrei na escola, mesmo com as dificuldades procurei tirar boas notas. Minha primeira escola tinha um estado precário: faltava cadeira na hora de estudar, às vezes tínhamos que sentar no chão e a merenda, não era suficiente para o ano todo. A maioria dos alunos que cursava a primeira série do primeiro grau possuía a idade de treze e quatorze anos, o ensino era de má qualidade. Lembro-me também que às vezes saía de casa para a escola sem tomar o café da manhã, pois nem sempre tinha ia com o estômago doendo por não ter nada dentro. Eu vivia angustiado por nem sempre ter o pão para comer, ter que ir estudar com fome. Não é fácil! Quando às vezes, tinha merenda na escola, neste dia todos ficavam felizes. Não esqueçamos que a estrutura financeira da maioria das famílias brasileiras é alarmante. É por isso que muitos jovens ou uma considerável parcela é analfabeto, visto que não possuíram uma boa estrutura econômica e social na infância. Segundo Darcy Ribeiro:

A consciência da precariedade da escola oferecida à criança das classes populares- uma escola que como regra, não garante mais nem mesmo alguma capacidade de ler e escrever- tornou-se domínio 
público. A cada publicação de resultados de pesquisas dos níveis de aprendizagem das matérias escolares de alunos da rede pública brasileira de ensino médio e fundamental que confirma o desastre. Surgem editoriais e reportagens na mídia que denunciam o estado de coisas vigente.

\section{A DEFICIÊNCIA ECONÔMICA NA ESTRUTURA FAMÍLIAR}

Estudei até a quarta série na Escola Raimunda Barros, situada no Bairro Novo, onde passei momentos importantes. Nesta etapa da vida, tinha que dividir meu tempo entre o trabalho e a escola, por isso muitas vezes cheguei atrasado à escola, e volto a repetir: isso não era fácil. Depois que chegamos à cidade, tivemos que trabalhar na roça junto com meu avô, só para arrumar o pão que às vezes, nem sempre dava. O tempo que sobrava depois, claro, da escola, fazia pequenas vendas as quais ajudavam a custear a alimentação. Mesmo assim, às vezes, não dava. Somente quando sobrava é que mamãe comprava alguns materiais escolares para mim. O que faltava, a professora que conhecia a minha realidade me ajudava e assim eu fui batalhando. No ano de 1989, mudei de escola fui estudar na escola São João Batista, onde tudo começou a dar certo.

Nesse primeiro degrau da vida, senti uma responsabilidade maior nos estudos, pois fazia a quinta série e era um estudo com maior carga horária habitual. Enquanto isso continuava trabalhando na roça, produzindo farinha de mandioca e seus derivados. Minha mãe sempre estava endividada e quando recebia era só para entregar. Ainda bem que temos uma feira livre em Cametá rica em alimentação com preço acessível. Segundo o ditado popular: se correr o bicho pega e se ficar o bicho come; a vida não pode parar, pois o tempo não para. Nesta escola passei cinco anos estudando, tendo repetido um ano por motivo das dificuldades que vinha passando. Mas, enfim conclui o Ensino Fundamental, já estava no finalzinho do ano de 1993. Todos sabemos que famílias brasileiras vêm sofrendo por causa dessa dificuldade econômica, várias pesquisas comprovaram essa realidade, como a do ano de 1989 realizada pela UNICAMP e pelo NEEP, tendo como tema "Um estudo Sócio Econômico da Indigência e da Pobreza Urbana", apartir da qual faz- se a seguinte afirmação:

As políticas de combate à pobreza entraram na agenda nacional nos anos 90 pela influência de vários fatores. O mais importante, sem

Revista PET Interdisciplinar e Programa Conexões /UFPA On-line. Ed. Especial - 2017, BELÉM/ PA - ISSN 2447-097X 
dúvida, foi a campanha nacional da Ação da Cidadania Contra a Fome, a Miséria e pela Vida, um dos mais importantes movimentos sociais dos últimos anos que, liderado pelo sociólogo Betinho, conclamou a sociedade brasileira a indignar-se e a mobilizar-se na luta contra a fome e a pobreza.

No ano seguinte, fui intimado para prestar serviço militar, sendo que nesse mesmo tempo eu havia sido aprovado no teste de seleção para ingressar na escola de segundo grau. Imediatamente tive que optar por outro colégio por motivo de coincidência de horário, já que tinha vontade de vencer na vida, e agora no segundo grau, mais próximo da universidade. Caro leitor como salientei anteriormente, somou-se uma responsabilidade a mais: ter que prestar serviço militar e estudar, mas, quem tem fé, Deus ajuda. Consegui conciliar o tempo: ia fardado para a escola durante seis meses, até concluir o tempo de serviço militar. Já estava na segunda metade do ano de 1994, cursando o segundo grau na área do magistério. Nessa etapa, me sentia ainda mais motivado, visto que estava me preparando para ser professor de primeira à quarta série do ensino fundamental. Neste momento pensei que iria conseguir um emprego, mas, em uma cidade politiqueira como a cidade de Cametá, jamais conseguiria um emprego se não estivesse na mesma cúpula desses políticos, visto que nem se falava em concurso público.

No ano seguinte, já cursando o segundo ano do magistério na escola Osvaldina Muniz, fui convidado para participar da eleição de fundação do grêmio estudantil da escola, onde fazia parte de uma comissão, obtendo grande êxito nas eleições e fundamos o Grêmio Estudantil Osvaldina Muniz (GEOM). Essa não foi uma realização só da escola, mas também nossa enquanto estudantes. Aprendi a ser uma pessoa crítica internamente, pois, geralmente na prática não se pode demonstrar isso, com medo de ser punido pelos professores e pela direção. Mas, quando se tratava de direitos estudantis, estava presente e por nada neste mundo trocaria o direito de entrar nesta luta em prol dos educandos. Houve novas eleições após dois anos, e o fim da nossa gestão foi no ano da minha formação na conclusão do magistério. E volto a explanar: nesse tempo, ainda trabalhava na lavoura da farinha da mandioca e nas vendas, no tempo vago; mas fazia isso com gosto, porque precisava sustentar o sonho de vencer na vida, conseguir um bom emprego e ter uma vida digna. José Maria Pereira destaca que Pesquisas feitas pelo FIPE (Fundação Instituto de Pesquisas Econômicas) constataram que:

Revista PET Interdisciplinar e Programa Conexões /UFPA On-line. Ed. Especial - 2017, BELÉM/ PA - ISSN 2447-097X 
Diante da violência do desemprego e, desprotegidos pelos sindicatos - que defendem os interesses apenas daqueles que são sindicalizados, ou seja, dos que ainda estão empregados no setor formal -, uma parte cada vez maior da população refugiou-se em diversos tipos de atividades informais, numa estratégia para garantir, ao menos, a sua sobrevivência. (p. 2)

Amigo leitor saiba que os brasileiros nunca desistem da luta. O desemprego estrutural faz com que muitos brasileiros trabalhem por conta própria em vendas nas feiras livres das cidades, garantindo assim a sua sobrevivência; por isso continuo lutando, porque acredito ser este o caminho para se chegar a um pedestal mais elevados.

Conclui o segundo grau no ano de 1996. Emprego, naquele momento, parecia ser fácil aparentemente, mas, na verdade, a luta foi grande e mesmo assim não consegui. Questioneime sobre o que fazer se eu não havia emprego tampouco condição para prosseguir nos estudos, visto que tive uma educação deficiente e uma estrutura familiar economicamente pobre. De que maneira um estudante de origem popular conseguiria continuar? Tais questionamentos surgiram, uma vez que nesse nível de escolaridade é feito uma seleção onde passam os mais preparados, ou seja, aqueles que tiveram uma estrutura educacional qualificada, enquanto outros são mantidos à margem, como é o caso da maioria dos alunos das escolas públicas.

No ano seguinte, tentei ingressar na universidade através do vestibular, mas não fui aprovado. A partir daquele momento não pude tentar de novo, pois não dispunha de recursos financeiros para isso. Em seguida, constitui família e as coisas ficaram mais difíceis ainda. Passei sete anos sem tocar em um livro ou caderno, mas guardei no peito a imensa vontade de um dia cursar a Universidade Federal do Pará. Em 2003, tentei novamente entrar, mas não consegui. Quando completei quatro tentativas seguidas, fui aprovado na área de Letras da Universidade Federal do Pará Campus de Cametá. Neste momento quebrei o tabu do jogo, consegui ultrapassar esta barreira que parecia tão difícil.

Esse foi um dos acontecimentos mais marcantes na minha vida de estudante. Consegui realizar um sonho e confesso que nunca senti nada igual. Essa é uma emoção única. A partir daí, senti meus pés no chão e estava ansioso para trilhar este novo espaço, pois, para mim, esta conquista representava, primeiramente, um emprego. Mais uma vez me enganei, 
porque agora é que não podia trabalhar, nem no mercado informal, visto que até mesmo nas lojas do comércio não aceitavam que se trabalhasse apenas quatro horas por dia, já que funcionavam por mais de oito horas diárias. Minha situação se complicou pelo fato de que o curso que optei é no horário da manhã, o mesmo horário em que eu fazia bico na feira livre da cidade. E bem sabemos que em Cametá o comercio só funciona ativamente no horário matutino.

Apesar das dificuldades, comecei a estudar, sem deixar para trás os pensamentos de como iria sobreviver durante quatro anos e seis meses. Consegui estudar apenas um semestre e uma disciplina do outro. Já estava prestes a desistir do estudo, mesmo não querendo, pois a necessidade de ganhar o sustento de minha família é que me forçava fazer tal escolha. Então, nesse momento oportuno, apareceu o programa "Conexão de Saberes" com cinco bolsas e logo em seguida a seleção. Graças a Deus fui contemplado com uma. Passei então a realizar troca de experiências e conhecimentos absorvidos nessa interação.

\section{A ADAPTAÇÃO EM MEIO AOS PROBLEMAS}

Estamos no ano de 2008, já se passaram dez meses após a implantação do programa que começou a funcionar no Campus de Cametá, em maio de 2007, visto que em algumas cidades do estado do Pará já existia anos antes. Amigo leitor, mesmo com as pedras no caminho eu absorvi muitos conhecimentos dentro do curso e o mais importante, aprendi a sobreviver com essas dificuldades. Espero chegar muito mais além dessa jornada, pois hoje estou no meu terceiro semestre do Curso de Letras, tendo de abrir mão de momentos importantes, como o convívio familiar, o trabalho que supria o sustento da família, e mudanças de hábitos no dia-dia. para chegar até aqui, mas isso faz parte da vida, onde nós somos os construtores de nossa própria realidade, tendo como ponto de partida a busca de um ideal.

\section{RECOMENDAÇÕES FINAIS}

A esperança de ser recompensado com o seu entendimento, sobre a vida de um estudante de origem popular às margens da sociedade burguesa, é muito importante, visto 
que, mesmo com as mudanças alcançadas ao longo dos tempos, ainda existem grandes obstáculos a serem vencidos. Mas num futuro bem próximo, através da liberdade de expressão, poderemos sobrepujá-los, transpondo as barreiras da sociedade capitalista. Mesmo sendo quase que uma utopia, temos que acreditar num futuro melhor para os nossos estudantes.

\section{Referências Bibliográficas}

BEJARANO, Selva Ribas. Programa de garantia de renda mínima: a experiência de Campinas. In: BAVA, Silvio Caccia (Organizador). Programa de Renda Mínima no Brasil: Impactos e Potencialidades. Disponível em: <www.idrc.ca/uploads/userS/11051078131caccia.doc> Acesso em: 27 de junho de 2008.

BÍBLIA SAGRADA. Velho Testamento, Eclesiastes, 3:2b. Disponível em <www.sacudidura.com/biblia/eclesiastes/> Acesso em: 30 de junho de 2008.

CHAUÍ, Marilena. Ideologia e Educação. São Paulo: nacional, 1980.

FURTER, Pierre. Educação e Reflexão. Petrópolis: Vozes, 1966.

MACHADO, João Luís Almeida. Cinema na Educação. Disponível em: $<$ http://www.planetaeducacao.com.br/novo/impressao.asp?artigo=20> Acesso em: 27 de junho de 2008.

MELO, Tiago de. faz-escuro-mas-eu-canto. Disponível em: <nossoclubedolivro.blogspot.com/2007/12/.html> Acesso em: 29 de junho de 2008.

PEREIRA, José Maria. Cooperativas de trabalho: Flexibilização ou Degradação do trabalho? Disponível em: <http://www.unifra.br/professores/pereirajm/projeto\%20FIPE.doc> Acesso em: 30 de junho de 2008.

Revista PET Interdisciplinar e Programa Conexões /UFPA On-line. Ed. Especial - 2017, BELÉM/ PA - ISSN 2447-097X 
PLATÃO. Apud ROCHA, Lutz F. da Silva \& SANTOS, Naumari Ferraz dos. Introdução. Coleção Caminhadas de universitários de origem popular/UFES. Rio de Janeiro- RJ: Universidade Federal do Rio de Janeiro, 2006.

REIS, Ricardo. (vários poemas). Disponível em: <www.geocities.com/marco_lx_pt/ods.htm> Acesso em: 29 de junho de 2008.

RIBEIRO, Darcy. Educação no Brasil. Disponível em: <www.PdtRj.Org.Br/Docs/EDUCAÇÃO\%20NO\%20BRASIL.Doc> Acesso em: 28 de junho de 2008. 